\title{
Retraction: Optimization of the design of a barbed suture for flexor tendon repair using extended finite element analysis
}

\author{
Joseph Bakhach, Ahmad Oneissi, Dimitri Bakhach, Reem Karami, Kobeissi Hiba, Shammas Elie \\ American University of Beirut Medical Center, Faculty of Medicine, Beirut 2020, Lebanon.
}

Corresponding to: Dr. Joseph Bakhach, American University of Beirut Medical Center, Faculty of Medicine, Beirut 2020, Lebanon. E-mail: yb11@aub.edu.lb

Received: 6 Aug 2018 Accepted: 8 Aug $2018 \quad$ Published: 10 Aug 2018

DOI: $10.20517 / 2347-9264.2018 .56$

The original article was published on 30 Jun 2018.

This article ${ }^{[1]}$ has been retracted by authors because there are unresolved issues relating to authorship and contents. All the authors confirmed this retraction.

\section{REFERENCE}

1. Joseph Bakhach, Ahmad Oneissi, Dimitri Bakhach, Reem Karami, Kobeissi Hiba, Shammas Elie. Optimization of the design of a barbed suture for flexor tendon repair using extended finite element analysis. Plast Aesthet Res 2018;5:21. 